\title{
Evaluation of ameliorative effect of sodium nitrate in experimental model of streptozotocin-induced diabetic neuropathy in male rats
}

\author{
Hajar Oghbaei ${ }^{1}$, Mohammad Reza Alipour ${ }^{2}$, Gisou Mohaddes ${ }^{3}$, \\ Gholam Reza Hamidi An ${ }^{4}$, Rana Keyhanmanesh ${ }^{5}$
}

\begin{abstract}
${ }^{1}$ Student Research Committee, Tabriz University of Medical Sciences, Tabriz, Iran; ${ }^{2}$ Tuberculosis and Lung Diseases Research Center, Tabriz University of Medical Sciences, Tabriz, Iran; ${ }^{3}$ Neurosciences Research Center, Tabriz University of Medical Sciences, Tabriz, Iran; ${ }^{4}$ Department of Basic Sciences, Faculty of Veterinary Medicine, University of Tabriz, Tabriz, Iran; ${ }^{5}$ Drug Applied Research Center, Tabriz University of Medical Sciences, Tabriz, Iran E-mail: rkeyhanmanesh@gmail.com
\end{abstract}

Objective. Diabetes induces sensory symptoms of neuropathy as positive (hyperalgesia), negative (hypoalgesia), or both.

Methods. In the present study, fifty male Wistar rats were allocated to five groups: control, control+nitrate, diabetes, diabetes+insulin, and diabetes+nitrate. Thirty days after diabetes confirmation, insulin (2-4 U/day) was injected subcutaneously in diabetes+insulin group and nitrate $(100 \mathrm{mg} / \mathrm{l})$ was added into drinking water of the control+nitrate and diabetes+nitrate groups for a period of 2 months. In order to assess the mechanical and thermal algesia, tail immersion, hot plate, and von Frey tests were performed. The serum insulin levels were determined with insulin ELISA Kit. Serum level of NOx was determined by the Griess method.

Results. Both thermal and mechanical nociceptive thresholds showed a significant decrease $(p<0.05)$ which was followed by a significant increase $(p<0.01)$ in the thermal nociceptive threshold in the diabetes group. Chronic nitrate or insulin treatment led to a significant decrease $(\mathrm{p}<0.01)$ in blood glucose levels, as well as a significant $(\mathrm{p}<0.05)$ increase in the body weight and serum NOx. Moreover, nitrate treatment significantly increased serum insulin levels $(\mathrm{p}<0.001)$ compared to the other groups.

Conclusion. Chronic nitrate treatment modified the thermal and mechanical sensitivities in diabetic animals.

Key words: sodium nitrate, diabetes, mechanical algesia, thermal algesia

Diabetic peripheral neuropathy is one of the most important complications of diabetes with ranges from $7 \%$ in the first year of diagnosis to $50 \%$ with more than 25 years (Pirart 1978). Diabetic peripheral neuropathy is characterized by massive and progressive demyelination, neuronal loss, and injured nerve regeneration, which finally can result in a loss of sensation in parts of the body, pain, foot ulceration, and lower limbs amputation (Yagihashi and Matsunaga 1979; Dyck and Giannini 1996; Vinik 1999; Vinik and Ziegler 2007). The severity of symptoms is correlated with duration of diabetes and the degree of hyperglycemia (Tesfaye et al. 2005). Hyperglycemia is proposed to be an important etiological factor in complications of diabetes (Hoybergs and Meert 2007). Hyperglycemia induces glucose flux via the excess activation of protein kinase $\mathrm{C}(\mathrm{PKC})$, accumulation of advanced glycation end (AGE) products, and polyol pathway hyperactivity (Forbes and Cooper 2013; Rask-Madsen and King 2013). Moreover, hyper-

Corresponding authors: Dr. Rana Keyhanmanesh, PhD., Professor of Physiology, Department of Physiology, Tabriz University of Medical Sciences, Tabriz, Iran; phone/fax: +98-41-33364664; e-mail: rkeyhanmanesh@gmail.com; Dr. Gisou Mohaddes, Neurosciences Research Center, Tabriz University of Medical Sciences, Tabriz, Iran; e-mail: gmohades@yahoo.com. 
glycemia in nerve fibers causes conversion of glucose to sorbitol by aldose reductase (AR), thereby causing the depletion of reduced glutathione (GSH) and nitric oxide (NO) due to the overconsumption of nicotinamide adenine dinucleotide phosphate (NADPH) (Obrosova 2009; Yagihashi et al. 2011). The oxidative stress caused by the activation of these pathways leads to functional and structural alterations of neural cells and vascular endothelial dysfunction resulting in the nerve blood flow reduction and endoneurial hypoxia associated with diabetic peripheral neuropathy (Yagihashi et al. 2011; Rask-Madsen and King 2013). Vascular influence on the development and progression of neuropathy has been further shown by studies on humans (Thrainsdottir et al. 2003; Malik et al. 2005; Rask-Madsen and King 2013). It has been observed that the vascular supply of peripheral nerves is very sparse and lacks autoregulation. Therefore, blood flow is likely to be compromised easily and makes peripheral nerves susceptible to ischemia (Smith et al. 1977).

Nitric oxide is an intracellular messenger synthesized from L-arginine by three isoforms of nitric oxide synthase (NOS), playing a crucial role in different physiological and pathological processes (Nathan and Xie 1994; Alderton et al. 2001). Another pathway for NO formation has previously been explained by Duncan et al. (1995), where nitrate is consecutively reduced to nitrite and then NO. Studies have shown several functions for NO such as reducing blood pressure and blood glucose levels, enhancing the pancreatic blood flow and insulin secretion, regulating microvascular blood flow and mitochondrial function, inhibiting platelet aggregation and endothelial cell dysfunction, modulating inflammation and oxidative stress, and modifying pain (California Healthcare Foundation 2003; Zochodne and Levy 2005; Webb et al. 2008; Parthasarathy and Bryan 2012). Reduced NO bioavailability has been reported in diabetic microvascular and macrovascular diseases (Porta et al. 1987; Milsom et al. 2002). However, some studies declared increased or unchanged NO concentrations in hyperglycemia and diabetes conditions (Mancusi et al. 1996; Cosentino et al. 1997). A recent study stated that an increased incidence of diabetes among children may be related to high nitrate concentrations in drinking water, however, other studies have shown beneficial effects of nitrate (Benson et al. 2010). In addition, chronic intake of a low dose of nitrate $(100 \mathrm{mg} / \mathrm{l} /$ day $)$ for 2 months protected the diabetic rat heart from ischemia-reperfusion injury by attenuating oxidative stress (Jeddi et al. 2016). Cardiac and renal protective effects of vegetables may relate to their high nitrate contents (Lundberg et al. 2006; Ohtake et al. 2007).

\section{Material and methods}

Animals. Fifty male Wistar albino rats $(85-115 \mathrm{~g}$, 6-7 weeks old) were obtained from animal house of Tabriz University of Medical Sciences. All animals were kept under standard laboratory conditions (12 h light/dark cycle, $20-22^{\circ} \mathrm{C}$, and $45-55 \%$ humidity) with free access to rat chow and water. After one week of habituation, animals were randomly allocated to five groups $(n=10)$ : control $(C$, did not received any intervention), control+nitrate $(\mathrm{CN}$, received $100 \mathrm{mg} / \mathrm{l}$ sodium nitrate in drinking water daily for 2 months), diabetes ( $\mathrm{D}$, did not received any intervention), diabetes+insulin (DI, received 2-4 U NPH insulin daily for 2 months), and diabetes+nitrate (DN, received $100 \mathrm{mg} / \mathrm{l}$ sodium nitrate in drinking water daily for 2 months). Two or three rats were kept together in standard cages in all groups, except for the $\mathrm{CN}$ and DN groups that each animal was housed individually.

All experimental protocols were approved by the Ethics Committee of Animal Research of Tabriz University of Medical Sciences (No. IR.TBZMED. REC.1395.960).

Induction of diabetes. Diabetes was induced by single i.p. injection of $60 \mathrm{mg} / \mathrm{kg}$ streptozotocin (Sigma-Aldrich, Germany) in sodium citrate buffer ( $\mathrm{pH} 4.5$ ). Three days later, blood (obtained from a tail vein) glucose levels were measured using a glucometer (Norditalia Elettromedicali S.r.I., Italy). Animals with glucose levels more than $250 \mathrm{mg} / \mathrm{dl}$ were considered diabetic and those with glucose levels less than $250 \mathrm{mg} / \mathrm{dl}$ were excluded from the study (Oghbaei et al. 2017).

Experimental design. All treatments were started one month after confirmation of diabetes. Animals in DI group received s.c. injection of NPH insulin (Pharmaceutical Mfg. Co., Iran) with a dose of 2-4 U/day (Keyhanmanesh et al. 2018). Insulin dose was adjusted according to the hyperglycemic condition for 2 months. Animals in the $\mathrm{CN}$ and $\mathrm{DN}$ groups received sodium nitrate (Merck KGaA, 64271 Darmstadt, Germany) that was added into their drinking water in a concentration of $100 \mathrm{mg} / \mathrm{l} /$ day for 2 months (Oghbaei et al. 2018). The water intake by each animal was measured every day. Baseline values for blood glucose levels and body weight were obtained at the beginning of the study and at 7th, 30th, 60th, and 90th days of experiment. Figures 1 and 2 shows the graphical abstract and experimental design respectively.

Assessment of thermal and mechanical sensitivities. In order to assess the thermal and mechanical sensitivities tail immersion, hot plate, and von Frey 


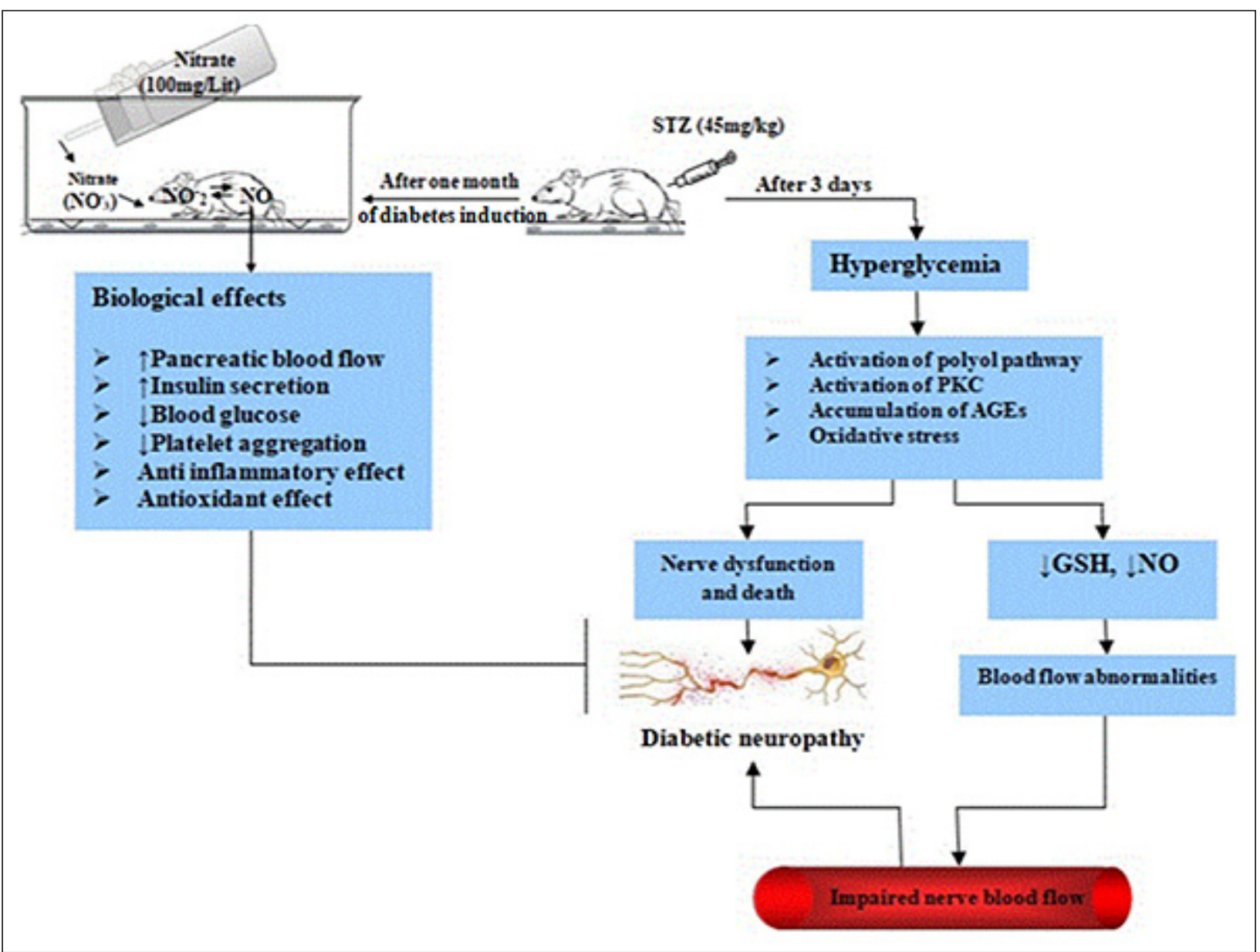

Figure 1. Graphical abstract. Abbreviations: $\mathrm{NO}_{3}{ }^{-}-$nitrate; $\mathrm{NO}_{2}{ }^{-}-$nitrite; $\mathrm{PKC}$ - protein kinase $\mathrm{C}$; AGEs - advanced glycation end products; GSH - glutathione; $\mathrm{NO}$ - nitric oxide.

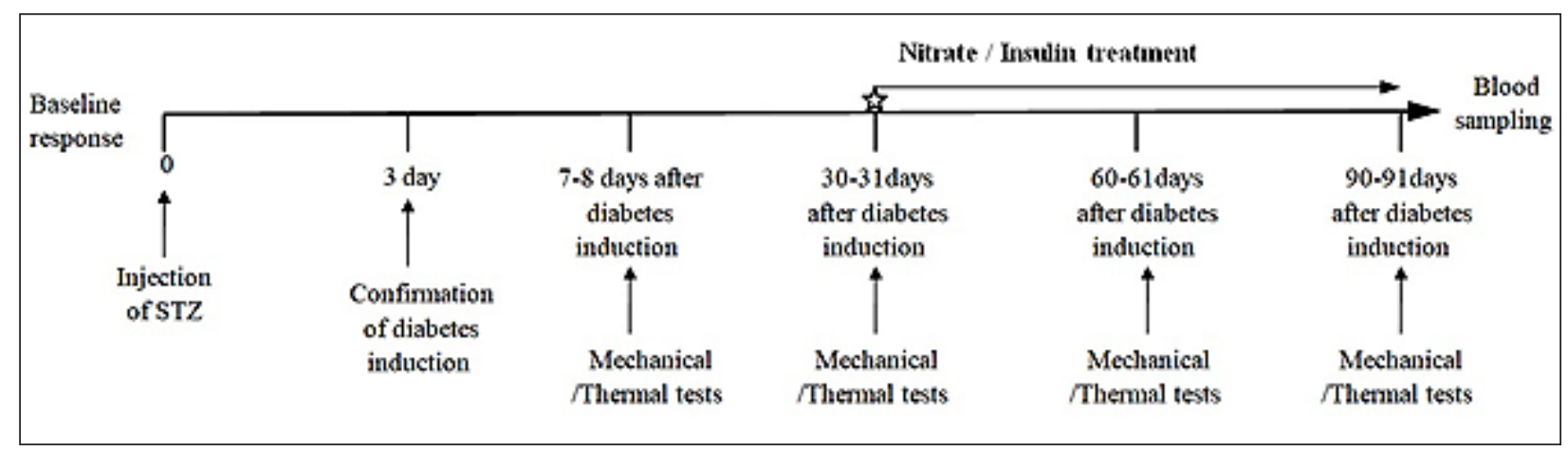

Figure 2. Experimental design. Abbreviations: STZ - streptozotocin.

tests were performed. All behavioral tests were performed between 8:00 a.m. and 2:00 p.m. in a quiet room. The tail immersion and von Frey tests were carried out on the same day with 1-2 hours interval. The hot plate test was performed on the first, 8th, 31st, 61st, and 91st days after diabetes induction. In all cases, baseline values were obtained for tail or paw withdrawal thresholds.

In order to assess the mechanical sensitivity (tactile allodynia), animals were put on an elevated metal mesh floor and allowed $30 \mathrm{~min}$ for habituation before the examination. Mechanical sensitivity was mea- 
sured by determining the paw withdrawal threshold using a series of von Frey filaments (Touch Test ${ }^{\text {tw }}$ Sensory Evaluator Kit, USA) in forces that ranged from 0.04 to $300 \mathrm{~g}$. The stimulus was applied vertically by filaments to the mid-plantar surface of the left and right hind paw three times for 2 seconds. The typical responses were considered as a lifting or shaking of the hind paw by stimulation. When a response was seen to the stimulus, a lighter filament was applied, and a heavier filament was tested in the absence of a response and at least two positive responses out of 3 trials were needed to define the positive response (Dobson et al. 2004).

The thermal sensitivity was assessed by both spinal (tail immersion) and supraspinal (hot plate) pain tests. In brief, rats were restrained and the distal 5 $\mathrm{cm}$ of their tail was dipped into the hot water bath maintained at $48 \pm 0.5^{\circ} \mathrm{C}$. Then, the tail withdrawal latency (sudden withdrawal of the tail) was recorded. A cut-off of the point of 40 seconds was used to keep away from damage to the tail for all groups (Zeng et al. 2014).

In hot plate test, animals were placed individually on a hot plate with the temperature adjusted and maintained to $53 \pm 0.5^{\circ} \mathrm{C}$. Positive responses were defined as a licking and/or jumping withdrawal of paws to pain stimulus. Reaction time or latency period for each animal was recorded during the examination period. A cut-off time of $40 \mathrm{~s}$ was used to prevent any probable paw damage (Kubo et al. 2009).

Blood sampling. At the end of the behavioral tests, all animals were deeply anesthetized with i.p. injection of ketamine $(80 \mathrm{mg} / \mathrm{kg})$ and xylazine $(10 \mathrm{mg} / \mathrm{kg})$. Blood samples were collected from the inferior vena cava and centrifuged at $3500 \mathrm{rpm}$ for $10 \mathrm{~min}$. Then, sera were separated and frozen at $-80^{\circ} \mathrm{C}$ until the analysis.

Measurement of serum insulin and NO metabolites (NOx) levels. The level of insulin in sera was measured by enzyme-linked immunosorbent assay (ELISA) kits (SHANGHAICRYSTAL DAY BIOTECH CO., LTD, China) according to the manufacturer's protocols.

Nitric oxide is a very unstable molecule with a short half-life and reacts with molecular $\mathrm{O}_{2}$ and accumulates in plasma or serum as nitrite $\left(\mathrm{NO}_{2}{ }^{-}\right)$and nitrate $\left(\mathrm{NO}_{3}{ }^{-}\right)$ions, therefore the quantification of NO metabolites (NOx) in biological samples provides valuable information with regards to NO production. The levels of NOx in the sera were measured using the Griess method. In brief, $\mathrm{NO}$ is quickly converted into the $\mathrm{NO}_{2}{ }^{-}$, and then $\mathrm{HNO}_{2}$ in an acidic solution. Finally, in the reaction with sulfanilamide, $\mathrm{HNO}_{2}$ forms a diazonium salt, which reacts with $\mathrm{N}$-(1-naphthyl) ethylenediamine $2 \mathrm{HCl}$ to form an azo dye which its absorbance was detected at $540 \mathrm{~nm}$. NOx levels were expressed as nmol and sodium nitrite was used as a standard (Rezabakhsh et al. 2017).

Statistical analysis. Statistical analysis was performed with SPSS version 16 statistic software package. All results are expressed as mean \pm S.E.M. A oneway repeated measures (ANOVA) analysis followed by Bonferroni modified t-test was used to determine the significance of differences in thermal and mechanical sensitivities. For all other variables, Oneway ANOVA analysis followed by Tukey's post-hoc test was performed. In all cases, $\mathrm{p}<0.05$ was considered as statistically significant.

\section{Results}

Effect of nitrate treatment on the mechanical sensitivity in diabetes. The results indicated that mechanical nociceptive threshold (tested by von Frey filaments) in the $\mathrm{D}$ group was significantly less than C group on the 7 th $(\mathrm{p}<0.01)$ and 30 th $(\mathrm{p}<0.001)$ days (Figure 3). Nitrate and insulin significantly modified diabetes-induced mechanical hyperalgesia on the 60th and 90th days after the induction of diabetes. In addition, mechanical nociceptive threshold in the D group significantly $(\mathrm{p}<0.01)$ was decreased on the 30 th day and continued all over the experimental period. There was a statistically significant $(\mathrm{p}<0.01)$ decrease in the mechanical nociceptive threshold of $\mathrm{DN}$ and DI groups on the 7th and 30th days and a significant increase $(p<0.01)$ on the 60th and 90th days compared to baseline (Figure 3).

Effect of nitrate treatment on thermal sensitivity in diabetes. Thermal allodynia threshold was assessed by a hot plate test. The control and CN groups showed no significant changes in thermal nociceptive threshold (Figure 4). No significant differences in thermal nociceptive threshold were also observed on the first and the 8th days after the induction of diabetes between the groups (Figure 4). However, the results showed a statistically significant $(p<0.01)$ decrease in thermal nociceptive threshold (hyperalgesia) in D, DI, DN rats on the 31st day after the induction of diabetes compared to the $\mathrm{C}$ group. Moreover, the thermal nociceptive threshold showed no significant difference on the 61st day after the induction of diabetes between the groups. The hot plate withdrawal latency of $\mathrm{D}$ group was significantly higher than the $\mathrm{C}(\mathrm{p}<0.01), \mathrm{CN}(\mathrm{p}<0.01), \mathrm{DN}(\mathrm{p}<0.001)$, and DI $(\mathrm{p}<0.001)$ groups on the 91st day after the diabetes induction. Moreover, data demonstrated that admin- 
Figure 3. Effect of nitrate treatment on the mechanical nociceptive threshold in diabetes. Data are shown as mean \pm SEM for 10 animals per group. Repeated measures oneway ANOVA and Bonferroni posttest were used. ${ }^{* *} \mathrm{p}<0.01$.

Figure 4. Effect of nitrate treatment on the thermal nociceptive threshold in diabetes in a hot-plate test. Data are shown as mean \pm SEM for 10 animals per group. Repeated measures one-way ANOVA and Bonferroni post-test were used. ${ }^{*} \mathrm{p}<0.05$, ${ }^{* *} \mathrm{p}<0.01$.
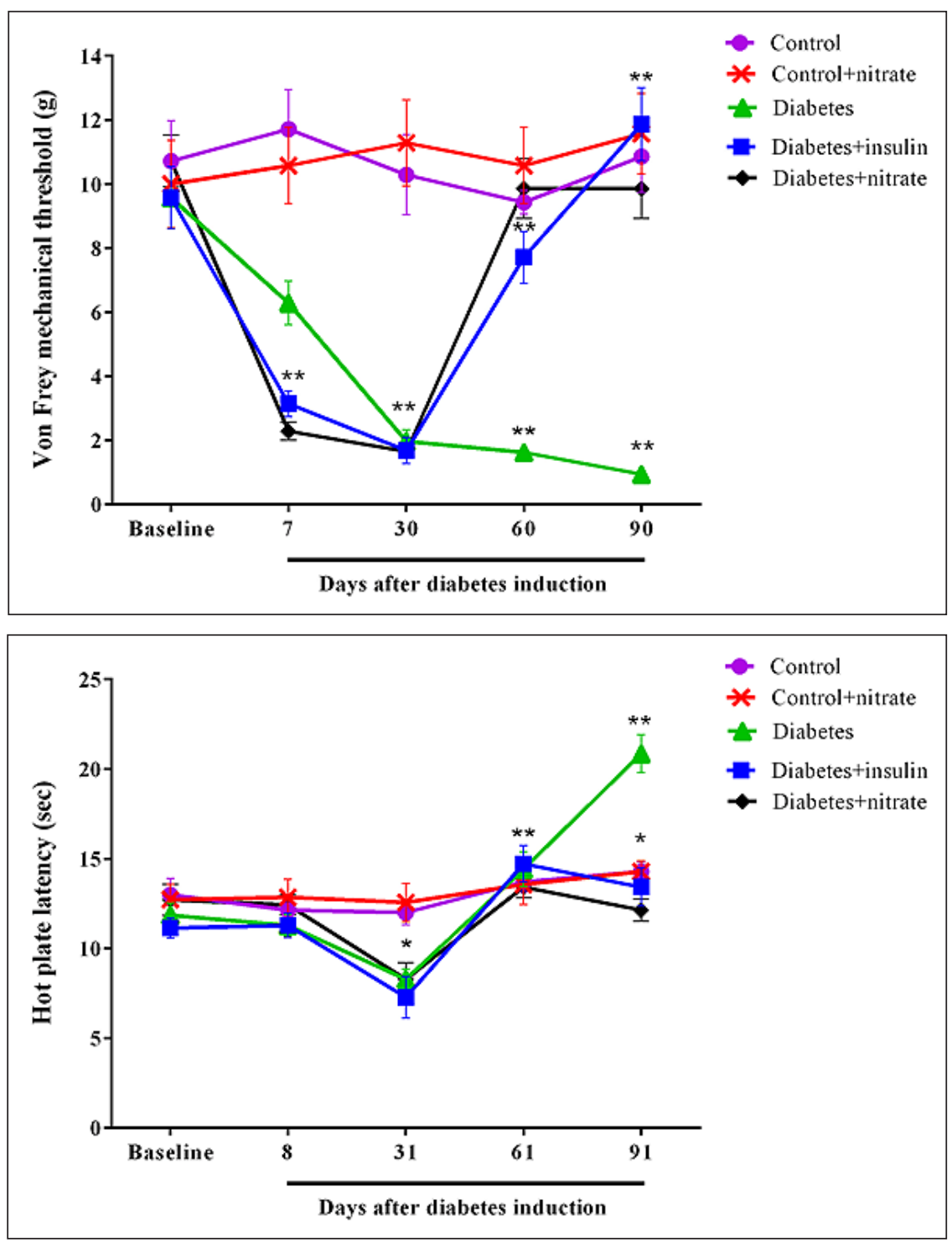

istration of inorganic nitrate or insulin significantly modified diabetes-induced thermal hyperalgesia on the 91st day after the induction of diabetes (Figure 4).

One-way ANOVA (repeated measure design) showed a significant decrease $(\mathrm{p}<0.05)$ on the 31 st day after the induction of diabetes and a significant $(p<0.01)$ increase on the 91st day after the induction of diabetes in thermal nociceptive threshold compared with baseline in the $\mathrm{D}$ group. A significant decrease in the thermal nociceptive threshold was observed in DN and DI groups on the 31st day after the induction of diabetes compared with the baseline $(p<0.05)$. Moreover, the thermal nociceptive threshold in the DI and DN groups were significantly higher than D group on the 61st day after the induction of diabetes and close to the $\mathrm{C}$ group on the 91st day after the induction of diabetes $(\mathrm{p}<0.05)$ (Figure 4$)$.

Tail immersion test is used for the evaluation of a nociceptive reaction in rodents. The results of the tail immersion test showed that nitrate $(\mathrm{p}<0.01)$ or insulin $(\mathrm{p}<0.001)$ treated groups had significantly higher tail withdrawal latency on the 90th day after the induction of diabetes compared to D animals (Figure 5). In addition, insulin injection in DI group significantly $(\mathrm{p}<0.001)$ increased tail withdrawal latency on the 60th day after the induction of diabetes compared to the $\mathrm{D}$ group. In addition, the thermal nociceptive threshold in the C, CN, DI, and DN groups were significantly $(\mathrm{p}<0.01)$ higher on the 7 th and 90th days after the induction of diabetes than the baseline (Figure 5). 


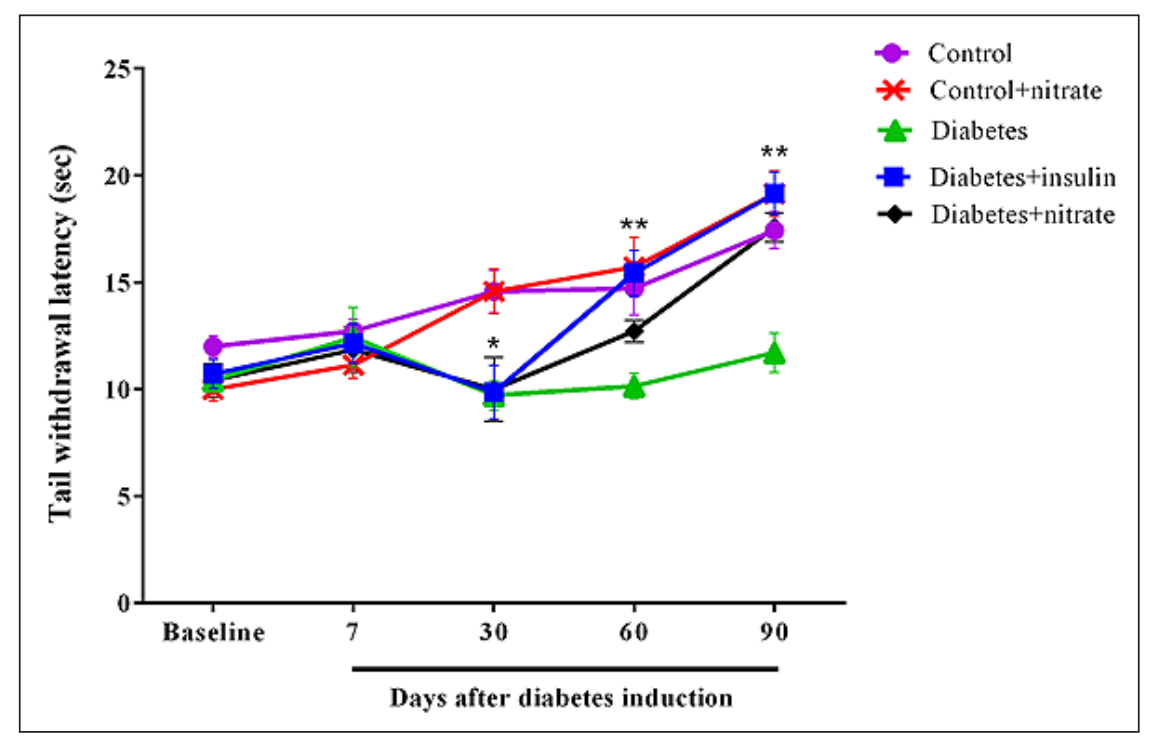

Figure 5. Effect of nitrate treatment on thermal nociceptive threshold in diabetes in a tail immersion test. Data are shown as mean \pm SEM for 10 animals per group. Repeated measures one-way ANOVA and Bonferroni post-test were used. ${ }^{*} \mathrm{p}<0.05$, ${ }^{* *} \mathrm{p}<0.01$.

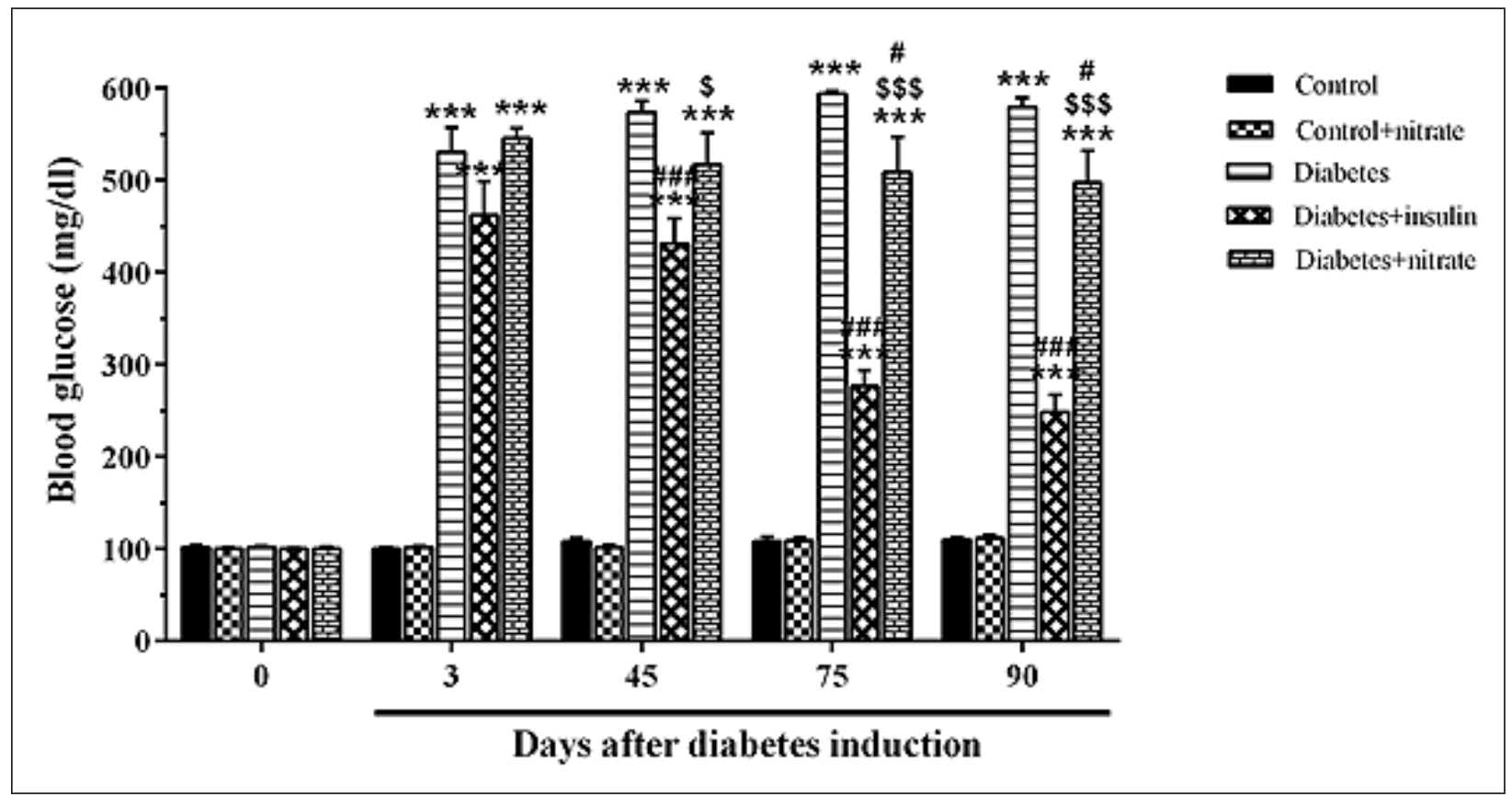

Figure 6. Effect of nitrate treatment on blood glucose levels in diabetes. Data are shown as mean \pm SEM for 10 animals per group. Data was analyzed using one-way ANOVA followed by Tukey's test. ${ }^{* * *} \mathrm{p}<0.001$ vs. C group; $\mathrm{*}<<0.05,{ }^{\# \# *} \mathrm{p}<0.001$ vs. D group; ${ }^{\$} \mathrm{p}<0.05,{ }^{\$ \$ \$} \mathrm{p}<0.001$ vs. DI group.

Effect of nitrate treatment on the blood glucose and body weight in diabetes. There were no significant differences in baseline blood glucose levels and body weights between the groups. Blood glucose levels of diabetes group were significantly higher than the control group $(\mathrm{p}<0.001)$. Insulin treatment in the DI group significantly decreased blood glucose levels compared to the D group $(\mathrm{p}<0.001)$. Nitrate treatment in the DN group also significantly decreased blood glucose levels in comparison to the $\mathrm{D}$ group on the 75th and 90th days after the induction of diabetes $(\mathrm{p}<0.05)$ (Figure 6).

Body weight showed a significant decrease in the diabetes group on the 75 th $(\mathrm{p}<0.05)$ and 90 th days after the induction of diabetes compared to the control group $(\mathrm{p}<0.001)$. However, insulin treatment in the DI group led to a significant increase in the final body weight compared to the $\mathrm{D}$ group $(\mathrm{p}<0.05)$. There 
was no statistically significant difference in the final body weight between DI and DN groups (Figure 7).

Effect of nitrate on serum insulin and NOx levels in diabetes. As illustrated in the Figure 8, serum insulin levels of the diabetes group were decreased significantly in comparison with the control group $(\mathrm{p}<0.01)$. Chronic nitrate treatment significantly increased the serum insulin levels in the DN group compared to the D group $(\mathrm{p}<0.001)$. Moreover, ni- trate treatment significantly increased serum insulin levels in the DN group in comparison to the DI group $(\mathrm{p}<0.001)$.

There was no significant difference in serum NOx levels of the $\mathrm{D}$ group in comparison to the $\mathrm{C}$ group. Nitrate treatment in both the DN $(\mathrm{p}<0.001)$ and CN $(\mathrm{p}<0.01)$ groups led to a significant increase in serum NOx levels. Moreover, insulin treatment significantly $(\mathrm{p}<0.05)$ increased serum NOx levels (Figure 9).

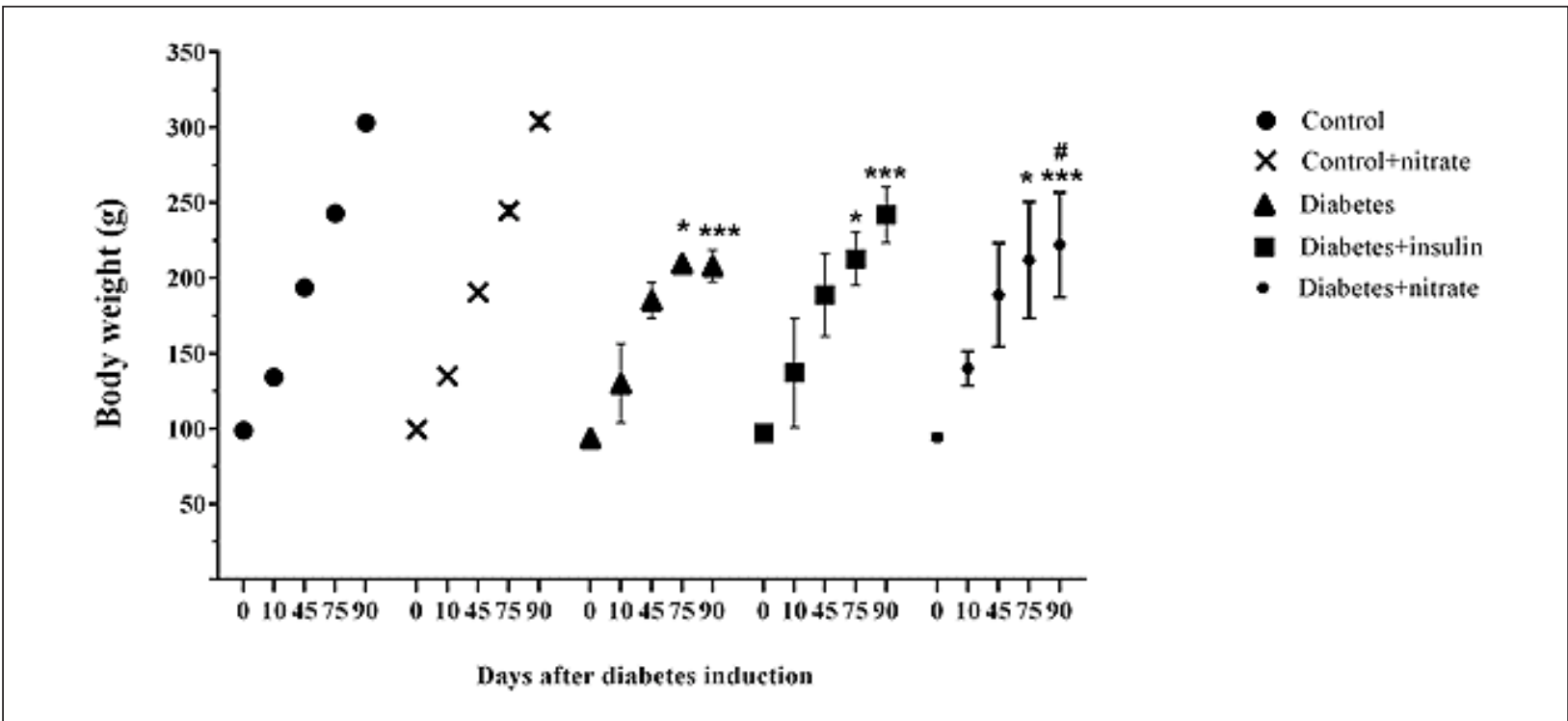

Figure 7. Effect of nitrate treatment on body weight in diabetes. Data are shown as mean \pm SEM for 10 animals per group. Data were analyzed using one-way ANOVA followed by Tukey's test. ${ }^{\star} \mathrm{p}<0.05,{ }^{* *} \mathrm{p}<0.001$ vs. C group; $\# \mathrm{p}<0.05$ vs. D group.

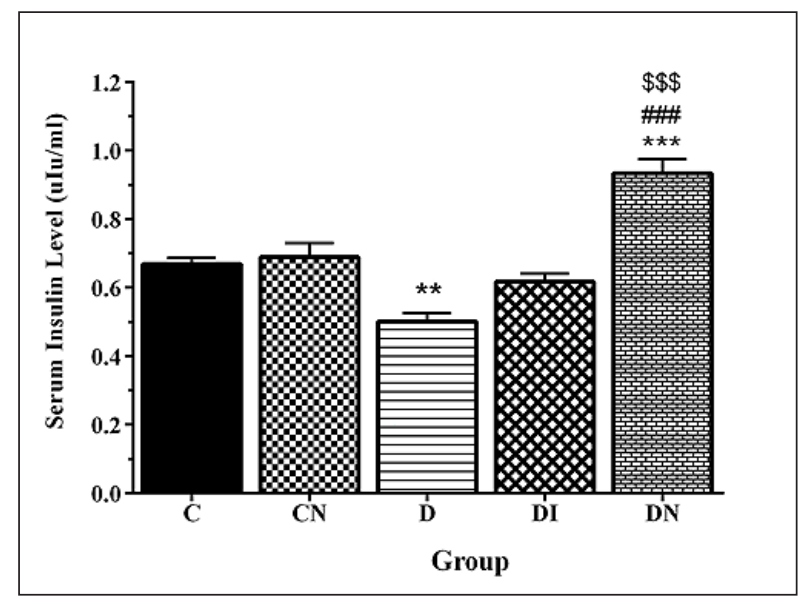

Figure 8. Effect of nitrate treatment on serum insulin levels in diabetes. Data are shown as mean \pm SEM for 10 animals per group. Comparisons were done by one-way ANOVA followed by Tukey's HSD test. ${ }^{* *} \mathrm{p}<0.01,{ }^{* * *} \mathrm{p}<0.001$ vs. C group;

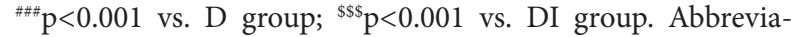
tions: C - control; CN - control+nitrate; D - diabetic; DI diabetes+insulin; $\mathrm{DN}$ - diabetes+nitrate.

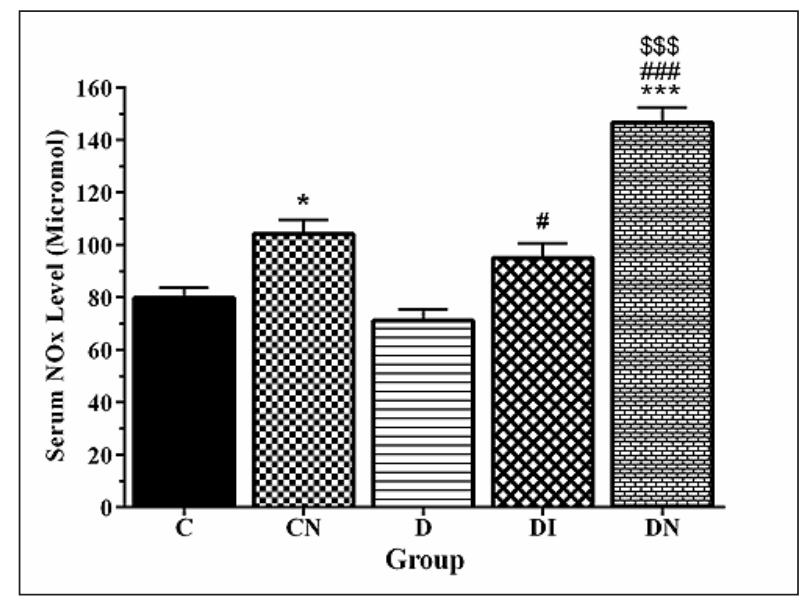

Figure 9. Effect of nitrate treatment on serum NOx levels in diabetes. Data are shown as mean \pm SEM for 10 animals per group. Comparisons were done by one-way ANOVA followed by Tukey's HSD test. ${ }^{*} \mathrm{p}<0.05,{ }^{* *} \mathrm{p}<0.001$ vs. C group; ${ }^{\# \#} \mathrm{p}<0.01,{ }^{\# \# \#} \mathrm{p}<0.001$ vs. D group; ${ }^{\$ \$ \$} \mathrm{p}<0.001$ vs. DI group. Abbreviations: $\mathrm{C}$ - control; $\mathrm{CN}$ - control+nitrate; D - diabetic; DI - diabetes+insulin; DN - diabetes+nitrate. 


\section{Discussion}

In the present study, mechanical and thermal sensitivities were investigated in rats with streptozotocininduced diabetes. Our findings showed that diabetes causes mechanical and thermal hyperalgesia, which was later followed by thermal (hot plate test) hypoalgesia. However, treatment with a low dose $(100 \mathrm{mg} / \mathrm{l} /$ day) of inorganic nitrate or NPH insulin (2-4 U/day) for 2 months significantly modified the diabetes-induced mechanical and thermal hyper/hypoalgesia.

Diabetic peripheral neuropathy is marked by paraesthesia, pain, and sensory loss (Duby et al. 2004). As described by Bolcskei et al. (2010) identification of "pain" because of its mental nature in animal models is challenging. However, there are some behavioral tests like hot-plate, tail withdrawal, and von Frey filaments that allow for the sensitive, reproducible, and rapid determination of the thermal and mechanical nociceptive thresholds in rats (Barrot 2012). This study showed that induction of diabetes causes thermal and mechanical hyperalgesia at the early stage and the thermal (hot plate test) hypoalgesia on the 91st day after the induction of diabetes. Mechanical hyperalgesia and thermal hyper/hypoalgesia have been previously reported in streptozotocin-induced diabetes in mice and rats (Calcutt et al. 2004; Gong et al. 2011). It has been shown that thermal and mechanical hyperalgesia is mediated by $\mathrm{C}$-fibers and A-fibers, respectively (Shir and Seltzer 1990; Khan et al. 2002). In line with our results, Dyck et al. (2000) reported decreased thermal perception threshold (hyperalgesia) in early stage and hypoalgesia in the late stage of the disease, which occurred simultaneously with degeneration of all types of peripheral nervous system fibers. Previous evidence has shown that spontaneous activity in the nociceptors of the peripheral nervous system causes some alterations in the central nervous system which is responsible for hyperalgesia (Yasuda et al. 2003; Duby et al. 2004).

Induction of diabetes in the present study did not significantly change serum NOx levels, however, nitrate treatment in diabetic animals significantly increased serum NOx levels. Our findings showed that 2 months nitrate treatment in control rats had no effects on serum NOx levels; a finding which could be surprising. Alteration of serum NO concentrations in diabetic conditions are controversial. Some studies have demonstrated that serum NO levels decreased in diabetic rats (Meininger et al. 2000; Jeddi et al. 2016). On the other hand, other studies have shown increased or unchanged NO levels in diabetes (Mancusi et al. 1996; Milsom et al. 2002; Adela et al. 2015).
It has been shown that hyperglycemia alters NO production through alteration of NOS gene expression (Cosentino et al. 1997; Cai et al. 2005; Zhang et al. 2014). Chakravarthy et al. (1998) have shown that high blood glucose exposure for 2-5 days decreased NOS expression in cultured retinal vascular endothelial cells of bovine. However, another study has reported a dose-dependent increase in NO concentrations in human umbilical vein endothelial cells (HUVEC) following four hours of high glucose exposure (Adela et al. 2015). Another study has shown that short-term (less than 5 years) hyperglycemia enhanced NO production, whereas long-term (more than 5 years) hyperglycemia exposure reduced it (Adela et al. 2015). These controversial results might be associated with the duration of diabetes, the severity of hyperglycemia, and the cell type. In the present study, serum NOx levels were measured three months after induction of the diabetes and it seems that some physiological mechanisms in the body have modified NO levels back to normal during this period.

Neuropathy, nephropathy, and retinopathy are among some of the diabetic microvascular complications (Fowler 2008). It has been reported that decreased bioavailability of endothelium-derived NO is involved in diabetic microvascular and macrovascular complications (Porta et al. 1987; Milsom et al. 2002). On the contrary, Maejimaa et al. (2001) it has been shown that enhanced plasma NO level in type 2 diabetic patients is associated with microvascular complications. Nakagawa (2009) has reported that physiological levels of $\mathrm{NO}$ generates low vascular permeability but too high or too low NO levels can result in hyper-permeability that in turn leads to glomerular injury and diabetic nephropathy. Therefore, a similar explanation can enlighten that both decreased and increased NO levels cause diabetic microvascular complications of nervous system, which may lead to the peripheral neuropathy.

The major finding of the present study was that inorganic nitrate treatment ameliorated diabetes-induced mechanical and thermal hyperalgesia. Mortada et al. (2017) have reported that enhancement of NO in diabetes, due to the increase in expression of iNOS in the spinal cord of rats, increased pain threshold in the diabetic group. However, Tanabe et al. (2009) have suggested that NO, is most probably produced via iNOS and nNOS in the spinal cord, mediated the neuropathic pain following peripheral nerve damage through both the NO-peroxynitrite and the NOcGMP-PKG pathways. These controversial results could be due to differences in NO levels, since previous studies have shown that low levels of $\mathrm{NO}$ are useful 
for some cellular functions (Jiang et al. 2014; Ohtake et al. 2015), whereas high levels of NO might cause harmful effects in the cells by peroxynitrite production (Pacher et al. 2007). Other mechanisms are also involved in diabetes hyper/hypoalgesia such as (ADPribose) polymerase (PARP), chemokines receptor activation, and endorphin levels reduction (Basbaum and Fields 1984; Obrosova et al. 2008; Sandireddy et al. 2014). Possible mechanisms that may NO affect the neuropathic pain threshold may include both direct and indirect effects. NO could directly influence the injured axons in the periphery and signal in the dorsal horn of the spinal cord, may indirectly influence the pain threshold by its benefit effect in decreasing the blood glucose (Basbaum and Fields 1984).

The present study also showed that insulin could prevent thermal and mechanical hyperalgesia and, ultimately, thermal hypoalgesia caused by diabetes. These findings are in agreement with the studies that have revealed mechanical hyperalgesia, thermal hypoalgesia, nerve conduction velocity, and the vibration perception threshold improved in type 1 and 2 diabetic rats following insulin therapy and maintaining normal blood glucose levels (Ohkubo et al. 1995; Calcutt et al. 1996; Srinivasan et al. 2000; Brussee et al. 2004). Moreover, it has previously been shown that insulin has useful effects on multiple symptoms of diabetic neuropathy, like an increase in nerve conduction velocity and reduction of hyperalgesia in the formalin test (Calcutt et al. 1996; Srinivasan et al. 2000; Brussee et al. 2004). Insulin may directly provide potent support of neurons and axons (insulin receptors on neuronal cells) through pathways that include the cerebrospinal fluid may influence diabetic algesia indirectly by its benefit effects on glycemia (Brussee et al. 2004).

The present investigation also showed that two months of nitrate therapy was associated with increased plasma insulin levels and body weight and decreased blood glucose concentration. The increased plasma insulin levels are possibly caused by nitrate induce-enhancing the pancreatic blood flow (Alm et al. 1999). Some studies have suggested that treatment with nitrate, nitrite, constitutive NOS (cNOS), and even L-arginine, as a NO precursor, increased the serum insulin levels (Schmidt et al. 1992; Alm et al. 1999; Carlstrom et al. 2010; Nystrom et al. 2012). Jeddi et al. (2016) have also reported that dietary nitrate improved glucose tolerance and prevented an increase in blood glucose levels. In addition, Cosby et al. (2003) have revealed that nitrite injection was followed by enhancing plasma insulin levels with no glycemic changes. On the contrary, Sjoholm (1996) have reported that in pancreatic $\beta$ cells, upregulation of the inducible NOS enzyme (iNOS) in response to inflammatory factors, resulted in impaired function and death of $\beta$ cells (decreased insulin secretion) in type 1 diabetes. These controversies are possibly due to various effects of nitric oxide in various concentrations. Previous studies have shown the concentration-dependency effects of NO with beneficial effects of a low dose of nitrate (Jiang et al. 2014; Jeddi et al. 2016). In this study, we hypothesized that nitrateinduced decrease in blood glucose levels was due to nitrate effects on serum insulin levels.

Similar to other studies, in our study the body weight showed a significant decrease in the diabetes group (Calcutt et al. 2004; Obrosova et al. 2008; Khalifi et al. 2015), which was modified by insulin therapy. Calcutt et al. (1996) have shown that insulin therapy for 8 weeks, modified body weight at the end of this period. Nitrate treatment in the current study also led to a significant increase in the final body weight compared to D group, which is possibly due to nitrate-induced increase in insulin levels and food intake (Nystrom et al. 2012).

Other beneficial effects of nitrate such as enhancing the pancreatic blood flow, regulating microvascular blood flow and mitochondrial function, inhibiting endothelial cell dysfunction, modulating inflammation and oxidative stress possibly play a role in modification of nociception in diabetes, which are strongly suggested to be investigated.

\section{Conclusions}

To our knowledge, this is the first report showing that a low dose of inorganic nitrate has a protective effect against thermal and mechanical hyperalgesia induced by diabetes. In conclusion, a novel role of nitrate was reported on modulation of pain threshold in diabetic rats. Nitrate might play a vital role as a neuroprotective agent and therefore, a diet containing nitrate along with insulin therapy in diabetic patients is likely to be proposed in the future.

\section{Acknowledgement}

This is a report of a database from the study "The effect of inorganic nitrate on the prevention and treatment of peripheral diabetic neuropathy in type 1 diabetic male rats" registered in student research committee of Tabriz University of Medical Sciences. All experimental protocols were approved by the Ethics Committee of Animal Research of Tabriz University of Medical Sciences (No. IR.TBZMED. REC.1395.960).” 


\section{References}

Adela R, Nethi SK, Bagul PK, Barui AK, Mattapally S, Kuncha M, Patra CR, Reddy PN, Banerjee SK. Hyperglycaemia enhances nitric oxide production in diabetes: a study from South Indian patients. PloS One 10, e0125270, 2015.

Alderton WK, Cooper CE, Knowles RG. Nitric oxide synthases: structure, function and inhibition. Biochem J 357, 593-615, 2001.

Alm P, Ekstrom P, Henningsson R, Lundquist I. Morphological evidence for the existence of nitric oxide and carbon monoxide pathways in the rat islets of Langerhans: an immunocytochemical and confocal microscopical study. Diabetologia 42, 978-986, 1999.

Barrot M. Tests and models of nociception and pain in rodents. Neuroscience 211, 39-50, 2012.

Basbaum AI, Fields HL. Endogenous pain control systems: brainstem spinal pathways and endorphin circuitry. Annu Rev Neurosci 7, 309-338, 1984.

Benson VS, VanLeeuwen JA, Taylor J, Somers GS, McKinney PA, Van Til L. Type 1 diabetes mellitus and components in drinking water and diet: a population-based, case-control study in Prince Edward Island, Canada. J Am Coll Nutr 29, 612-624, 2010.

Bolcskei K, Petho G, Szolcsanyi J. Noxious heat threshold measured with slowly increasing temperatures: novel rat thermal hyperalgesia models. In Analgesia, Humana Press, Totowa, NJ 57-66, 2010.

Brussee V, Cunningham FA, Zochodne DW. Direct insulin signaling of neurons reverses diabetic neuropathy. Diabetes 53, 1824-1830, 2004.

Cai S, Khoo J, Channon KM. Augmented BH4 by gene transfer restores nitric oxide synthase function in hyperglycemic human endothelial cells. Cardiovasc Res 65, 823-831, 2005.

Calcutt NA, Jorge MC, Yaksh TL, Chaplan SR. Tactile allodynia and formalin hyperalgesia in streptozotocin-diabetic rats: effects of insulin, aldose reductase inhibition and lidocaine. Pain 68, 293-299, 1996.

Calcutt NA, Freshwater JD, Mizisin AP. Prevention of sensory disorders in diabetic Sprague-Dawley rats by aldose reductase inhibition or treatment with ciliary neurotrophic factor. Diabetologia 47, 718-724, 2004.

California Healthcare Foundation/American Geriatrics Society Panel in Improving Care for Elders with Diabetes C. Guidelines for improving the care of the older person with diabetes mellitus. Journal of the American Geriatrics Society 51, 265-280, 2003.

Carlstrom M, Larsen FJ, Nystrom T, Hezel M, Borniquel S, Weitzberg E, Lundberg JO. Dietary inorganic nitrate reverses features of metabolic syndrome in endothelial nitric oxide synthase-deficient mice. Proc Natl Acad Sci U S A 107, 17716-17720, 2010.

Chakravarthy U, Hayes RG, Stitt AW, McAuley E, Archer DB. Constitutive nitric oxide synthase expression in retinal vascular endothelial cells is suppressed by high glucose and advanced glycation end products. Diabetes 47, 945-952, 1998.

Cosby K, Partovi KS, Crawford JH, Patel RP, Reiter CD, Martyr S, Yang BK, Waclawiw MA, Zalos G, Xu X, Huang KT, Shields H, Kim-Shapiro DB, Schechter AN, Cannon RO 3rd, Gladwin MT. Nitrite reduction to nitric oxide by deoxyhemoglobin vasodilates the human circulation. Nat Med 9, 1498-1505, 2003.

Cosentino F, Hishikawa K, Katusic ZS, Luscher TF. High glucose increases nitric oxide synthase expression and superoxide anion generation in human aortic endothelial cells. Circulation 96, 25-28, 1997.

Dobson CF, Tohyama Y, Diksic M, Hamel E. Effects of acute or chronic administration of anti-migraine drugs sumatriptan and zolmitriptan on serotonin synthesis in the rat brain. Cephalalgia 24, 2-11, 2004.

Duby JJ, Campbell RK, Setter SM, Rasmussen KA. Diabetic neuropathy: an intensive review. Am J Health Syst Pharm 61, 160-173, 2004.

Duncan C, Dougall H, Johnston P, Green S, Brogan R, Leifert C, Smith L, Golden M, Benjamin N. Chemical generation of nitric oxide in the mouth from the enterosalivary circulation of dietary nitrate. Nat Med 1, 546-551, 1995.

Dyck PJ, Giannini C. Pathologic alterations in the diabetic neuropathies of humans: a review. J Neuropathol Exp Neurol 55, 1181-1193, 1996.

Dyck PJ, Larson TS, O’Brien PC, Velosa JA. Patterns of quantitative sensation testing of hypoesthesia and hyperalgesia are predictive of diabetic polyneuropathy: a study of three cohorts. Nerve growth factor study group. Diabetes Care 23, 510-517, 2000.

Forbes JM, Cooper ME. Mechanisms of diabetic complications. Physiol Rev 93, 137-188, 2013.

Fowler MJ. Microvascular and macrovascular complications of diabetes. Clinical Diabetes 26, 77-82, 2008. 
Gong YH, Yu XR, Liu HL, Yang N, Zuo PP, Huang YG. Antinociceptive effects of combination of tramadol and acetaminophen on painful diabetic neuropathy in streptozotocin-induced diabetic rats Acta Anaesthesiol Taiwan 49, 16-20, 2011.

Hoybergs YM, Meert TF. The effect of low-dose insulin on mechanical sensitivity and allodynia in type I diabetes neuropathy. Neurosci Lett 417, 149-154, 2007.

Jeddi S, Khalifi S, Ghanbari M, Bageripour F, Ghasemi A. Effects of nitrate intake on myocardial ischemia-reperfusion injury in diabetic rats. Arq Bras Cardiol 107, 339-347, 2016.

Jiang H, Torregrossa AC, Potts A, Pierini D, Aranke M, Garg HK, Bryan NS. Dietary nitrite improves insulin signaling through GLUT4 translocation. Free Radic Biol Med 67, 51-57, 2014.

Keyhanmanesh R, Hamidian G, Alipour MR, Ranjbar M, Oghbaei H. Protective effects of sodium nitrate against testicular apoptosis and spermatogenesis impairments in streptozotocin-induced diabetic male rats. Life Sci 211, 63-73, 2018.

Khalifi S, Rahimipour A, Jeddi S, Ghanbari M, Kazerouni F, Ghasemi A. Dietary nitrate improves glucose tolerance and lipid profile in an animal model of hyperglycemia. Nitric Oxide 44, 24-30, 2015.

Khan GM, Chen SR, Pan HL. Role of primary afferent nerves in allodynia caused by diabetic neuropathy in rats. Neuroscience 114, 291-299, 2002.

Kubo K, Nishikawa K, Ishizeki J, Hardy-Yamada M, Yanagawa Y, Saito S. Thermal hyperalgesia via supraspinal mechanisms in mice lacking glutamate decarboxylase 65. J Pharmacol Exp Ther 331, 162-169, 2009.

Lundberg JO, Feelisch M, Bjorne H, Jansson EA, Weitzberg E. Cardioprotective effects of vegetables: is nitrate the answer? Nitric Oxide 15, 359-362, 2006.

Maejima K, Nakano S, Himeno M, Tsuda SI, Makiishi H, Ito T, Nakagawa A, Kigoshi T, Ishibashi T, Nishio M, Uchida K. Increased basal levels of plasma nitric oxide in type 2 diabetic subjects: relationship to microvascular complications. J Diabetes Complications 15, 135-143, 2001.

Malik RA, Tesfaye S, Newrick PG, Walker D, Rajbhandari SM, Siddique I, Sharma AK, Boulton AJ, King RH, Thomas PK, Ward JD. Sural nerve pathology in diabetic patients with minimal but progressive neuropathy. Diabetologia 48, 578-585, 2005.

Mancusi G, Hutter C, Baumgartner-Parzer S, Schmidt K, Schutz W, Sexl V. High-glucose incubation of human umbilical-vein endothelial cells does not alter expression and function either of G-protein a-subunits or of endothelial NO synthase. Biochem J 315, 281-287, 1996.

Meininger CJ, Marinos RS, Hatakeyama K, Martinez-Zaguilan R, Rojas JD, Kelly KA, Wu G Impaired nitric oxide production in coronary endothelial cells of the spontaneously diabetic BB rat is due to tetrahydrobiopterin deficiency. Biochem J 349, 353-356, 2000.

Milsom A, Jones C, Goodfellow J, Frenneaux M, Peters J, James P. Abnormal metabolic fate of nitric oxide in Type I diabetes mellitus. Diabetologia 45, 1515-1522, 2002.

Mortada Y, Khojasteh K, Zarei M, Mansouri A, Jorjani M. How nitric oxide increases in diabetic morphine tolerated male rats. Iran J Pharm Res 16, 630-639, 2017.

Nakagawa T. A new mouse model resembling human diabetic nephropathy: uncoupling of VEGF with eNOS as a novel pathogenic mechanism. Clin Nephrol 71, 103-109, 2009.

Nathan C, Xie QW. Regulation of biosynthesis of nitric oxide. J Biol Chem 269, 13725-13728, 1994.

Nystrom T, Ortsater H, Huang Z, Zhang F, Larsen FJ, Weitzberg E, Lundberg JO, Sjoholm A. Inorganic nitrite stimulates pancreatic islet blood flow and insulin secretion. Free Radic Biol Med 53, 1017-1023, 2012.

Obrosova IG, Xu W, Lyzogubov VV, Ilnytska O, Mashtalir N, Vareniuk I, Pavlov IA, Zhang J, Slusher B, Drel VR. PARP inhibition or gene deficiency counteracts intraepidermal nerve fiber loss and neuropathic pain in advanced diabetic neuropathy. Free Radic Biol Med 44, 972-981, 2008.

Obrosova IG. Diabetes and the peripheral nerve. Biochim Biophys Acta 1792, 931-940, 2009.

Oghbaei H, Asl NA, Sheikhzadeh F. Can regular moderate exercise lead to changes in miRNA-146a and its adapter proteins in the kidney of streptozotocin-induced diabetic male rats? Endocr Regul 51, 145-152, 2017.

Oghbaei H, Alipour MR, Hamidian G, Ahmadi M, Ghorbanzadeh V, Keyhanmanesh R. Two months sodium nitrate supplementation alleviates testicular injury in streptozotocin-induced diabetic male rats. Exp Physiol 103, 1603-1617, 2018.

Ohkubo Y, Kishikawa H, Araki E, Miyata T, Isami S, Motoyoshi S, Kojima Y, Furuyoshi N, Shichiri M. Intensive insulin therapy prevents the progression of diabetic microvascular complications in Japanese patients with non-insulin-dependent diabetes mellitus: a randomized prospective 6-year study. Diabetes Res Clin Pract 28, 103-117, 1995. 
Ohtake K, Ishiyama Y, Uchida H, Muraki E, Kobayashi J. Dietary nitrite inhibits early glomerular injury in streptozotocin-induced diabetic nephropathy in rats. Nitric Oxide 17, 75-81, 2007.

Ohtake K, Nakano G, Ehara N, Sonoda K, Ito J, Uchida H, Kobayashi J. Dietary nitrite supplementation improves insulin resistance in type 2 diabetic KKAy mice. Nitric Oxide 44, 31-38, 2015.

Pacher P, Beckman JS, Liaudet L. Nitric oxide and peroxynitrite in health and disease. Physiol Rev 87, 315-424, 2007.

Parthasarathy DK, Bryan NS. Sodium nitrite: The "cure" for nitric oxide insufficiency. Meat Sci 92, 274-279, 2012.

Pirart J. Diabetes mellitus and its degenerative complications: a prospective study of 4,400 patients observed between 1947 and 1973. Diabetes Care 1, 252-263, 1978.

Porta M, La Selva M, Molinatti P, Molinatti GM. Endothelial cell function in diabetic microangiopathy. Diabetologia 30, 601-619, 1987.

Rask-Madsen C, King GL. Vascular complications of diabetes: mechanisms of injury and protective factors. Cell Metab 17, 20-33, 2013.

Rezabakhsh A, Ahmadi M, Khaksar M, Montaseri A, Malekinejad H, Rahbarghazi R, Garjani A. Rapamycin inhibits oxidative/nitrosative stress and enhances angiogenesis in high glucose-treated human umbilical vein endothelial cells: role of autophagy. Biomed Pharmacother 93, 885-894, 2017.

Sandireddy R, Yerra VG, Areti A, Komirishetty P, Kumar A. Neuroinflammation and oxidative stress in diabetic neuropathy: futuristic strategies based on these targets. Int J Endocrinol 2014, 674987, 2014.

Schmidt HX, Warner TD, Ishii K, Sheng H, Murad F. Insulin secretion from pancreatic B cells caused by L-argininederived nitrogen oxides. Science 255, 721-723, 1992.

Shir Y, Seltzer ZE. A-fibers mediate mechanical hyperesthesia and allodynia and C-fibers mediate thermal hyperalgesia in a new model of causalgiform pain disorders in rats. Neurosci Lett 115, 62-67, 1990.

Sjoholm A. Nitric oxide donor SIN-1 inhibits insulin release. Am J Physiol 271, C1098-C1102, 1996.

Smith DR, Kobrine AI, Rizzoli HV. Absence of autoregulation in peripheral nerve blood flow. J Neurol Sci 33, 347$352,1977$.

Srinivasan S, Stevens M, Wiley JW. Diabetic peripheral neuropathy: evidence for apoptosis and associated mitochondrial dysfunction. Diabetes 49, 1932-1938, 2000.

Tanabe M, Nagatani Y, Saitoh K, Takasu K, Ono H. Pharmacological assessments of nitric oxide synthase isoforms and downstream diversity of NO signaling in the maintenance of thermal and mechanical hypersensitivity after peripheral nerve injury in mice. Neuropharmacology 56, 702-708, 2009.

Tesfaye S, Chaturvedi N, Eaton SE, Ward JD, Manes C, Ionescu-Tirgoviste C, Witte DR, Fuller JH, EURODIAB Prospective Complications Study Group. Vascular risk factors and diabetic neuropathy. N Engl J Med 352, 341-350, 2005.

Thrainsdottir S, Malik RA, Dahlin LB, Wiksell P, Eriksson KF, Rosen I, Petersson J, Greene DA, Sundkvist G. Endoneurial capillary abnormalities presage deterioration of glucose tolerance and accompany peripheral neuropathy in man. Diabetes 52, 2615-2622, 2003.

Vinik AI. Diabetic neuropathy: pathogenesis and therapy. Am J Med 107, 17S-26S, 1999.

Vinik AI, Ziegler D. Diabetic cardiovascular autonomic neuropathy. Circulation 115, 387-397, 2007.

Webb AJ, Patel N, Loukogeorgakis S, Okorie M, Aboud Z, Misra S, Rashid R, Miall P, Deanfield J, Benjamin N, MacAllister R. Acute blood pressure lowering, vasoprotective, and antiplatelet properties of dietary nitrate via bioconversion to nitrite. Hypertension 51, 784-790, 2008.

Yagihashi S, Matsunaga M. Ultrastructural pathology of peripheral nerves in patients with diabetic neuropathy. Tohoku J Exp Med 129, 357-366, 1979.

Yagihashi S, Mizukami H, Sugimoto K. Mechanism of diabetic neuropathy: where are we now and where to go? J Diabetes Investig 2, 18-32, 2011.

Yasuda H, Terada M, Maeda K, Kogawa S, Sanada M, Haneda M, Kashiwagi A, Kikkawa R. Diabetic neuropathy and nerve regeneration. Prog Neurobiol 69, 229-285, 2003.

Zeng P, Li S, Zheng YH, Liu FY, Wang JL, Zhang DL, Wei J. Ghrelin receptor agonist, GHRP-2, produces antinociceptive effects at the supraspinal level via the opioid receptor in mice. Peptides 55, 103-109, 2014.

Zhang X, Fu Y, Xu X, Li M, Du L, Han Y, Ge Y. PERK pathway are involved in NO-induced apoptosis in endothelial cells cocultured with RPE under high glucose conditions. Nitric Oxide 40, 10-16, 2014.

Zochodne DW, Levy D. Nitric oxide in damage, disease and repair of the peripheral nervous system. Cell Mol Biol (Noisy-le-grand) 51, 255-267, 2005. 